\title{
El periodismo de investigación en el caso Sodalicio
}

\author{
Investigative journalism in the Sodalicio case
}

Recibido: 26/11/2020

Aceptado: 09/08/2021

Publicado: 06/12/2021
Mariana Celis Arévalo u201413671@upc.edu.pe

https://orcid.org/0000-0002-3347-4742

Universidad Peruana de Ciencias Aplicadas, Perú

\section{Resumen}

El caso Sodalicio representa uno de los mayores escándalos de la Iglesia católica en el Perú, como consecuencia de la publicación denominada Mitad monjes, mitad soldados y de una serie de informes periodísticos en el diario La República, publicados en el año 2016. En nueve informes se revelan abusos de índole físico, sexual y psicológico contra sodálites, menores de edad, dentro del Sodalicio de Vida Cristiana, teniendo como denunciados de estos abusos a líderes de esta institución religiosa. Por lo tanto, el objetivo del presente trabajo es analizar y determinar las características de estos informes desde la perspectiva de la investigación periodística y considerando cuatro variables: criterios generales, elementos y características del periodismo de investigación, construcción narrativa y aspectos del Sodalicio de Vida Cristiana. La investigación es de tipo aplicada y de nivel descriptivo explicativo; el diseño es no experimental. La información de cada uno de los nueve informes se estructura de acuerdo a los siguientes ítems: titular, sentido del texto introductorio, cuerpo narrativo, protección de fuentes y fuentes de información.

Palabras clave: periodismo, periodismo de investigación, Sodalicio de Vida Cristiana, recursos literarios, análisis del discurso. 


\begin{abstract}
The Sodalicio case represents one of the biggest scandals of the Catholic Church in Peru, as a consequence of the publication called Half Monks, Half Soldiers and a series of journalistic reports in the newspaper La República, published in 2016. Nine reports reveal abuses of a physical nature, sexual and psychological against sodalites, minors, within the Sodalitium of Christian Life, having as denounced of these abuses leaders of this institution religious. Therefore, the objective of this work is to analyze and determine the characteristics of these reports from the perspective of journalistic investigation and considering four variables: general criteria, elements and characteristics of the investigative journalism, narrative construction and aspects of the Sodalitium of Christian Life. The research is of an applied type and of a descriptive and explanatory level; the design is non-experimental. Information from each of the nine reports is structure according to the following items: headline, meaning of the introductory text, narrative body, protection of sources and sources of information.
\end{abstract}

Keywords: journalism, investigative journalism, Sodalitium of Christian Life, literary resources, discourse analysis.

\title{
Introducción
}

El caso Sodalicio representa uno de los mayores escándalos de la Iglesia católica en el Perú. Se conoce a partir del 2015, luego de la investigación periodística y su publicación denominada Mitad monjes, mitad soldados realizada por los periodistas Pedro Salinas y Paola Ugaz, quienes posteriormente entre marzo y mayo del 2016, en una serie de informes del diario La República, presentan más testimonios y relatan de manera detallada el caso. En esos documentos se revelan abusos de índole físico, sexual y psicológico cometidos al interior de El Sodalicio de Vida Cristiana que, por más de dos décadas, dirigió Luis Figari, su fundador y quien actualmente, por orden del papa Francisco, permanece en Roma aislado de toda actividad relacionada a esta institución.

A partir de este contexto, surge la motivación por conocer ¿qué características tienen los nueve informes publicados sobre el caso Sodalicio en el diario La República entre marzo y mayo del 2016? Y, en función de esta interrogante, se plantean preguntas específicas como ¿qué recursos del periodismo de investigación se utilizaron en los informes del caso Sodalicio publicados en el diario La República?, ¿cómo se presentan los informes de investigación del caso Sodalicio desde una perspectiva 
narrativa?, y ¿cuáles son los aspectos del Sodalicio que se revelan en los informes publicados en el diario La República? El propósito, es ahondar en aspectos puntuales y relevantes de los mencionados informes y, con ello, contribuir en el ejercicio del periodismo de investigación.

Cabe mencionar que la mayor limitación, en esta investigación, fue encontrar documentación puntual sobre los informes del caso Sodalicio, solo existen notas informativas, reportajes o entrevistas que complementan la información publicada por los periodistas Pedro Salinas y Paola Ugaz. Sin embargo, sí es posible acceder a variada bibliografía respecto a definiciones de periodismo de investigación e instrumentos de análisis (Soto, 2012). Asimismo, se cuenta con estudios sobre las características del periodismo de investigación como fiscalizador de los grupos de poder y periodismo de investigación desde un enfoque digital (Martínez-Sanz y Durántez-Stolle, 2019; Rosales, 2013).

Por lo tanto, se plantea como objetivo general:

Determinar las características de los nueve informes publicados sobre el caso Sodalicio en el diario La República entre marzo y mayo del 2016.

Y, como objetivos específicos:

- Identificar los recursos del periodismo de investigación que se utilizaron en los informes del caso Sodalicio publicados en el diario La República.

- Describir la presentación de los informes sobre el caso Sodalicio publicados en el diario La República desde una perspectiva narrativa.

- Señalar los aspectos del Sodalicio que son revelados en los informes publicados en el diario La República.

\section{Marco teórico}

\section{El periodismo de investigación y sus características}

El periodismo de investigación tiene sus orígenes en la segunda mitad del siglo XX, gracias al trabajo de investigación de un equipo periodístico del diario The Washington Post que destapó el caso Watergate en Estados Unidos, lo que llevó a la renuncia del presidente Richard Nixon (Cebrián y Mirón, 2013, como se citó en Alire, 2017). 
La razón de ser del periodismo es la investigación, postulaba Gabriel García Márquez (1996). Más aún, en el periodismo de investigación, hay una mayor profundización en la recolección y contrastación de la información. En este sentido, el periodismo ayuda a los ciudadanos a reconocer a sus héroes y villanos, por lo que resulta fundamental que el periodista realice un buen trabajo de verificación de la información (Kovach y Rosenstiel, 2012). Por ello, el proceso que se sigue en el periodismo de investigación, hasta publicar la información, puede tomar semanas, meses o años, ya que esta debe ser publicada una vez que se tenga la información completa en torno a un caso y luego de pasar por un amplio proceso de contrastación (Caminos, 1997).

Al respecto, Gorriti (como se citó en Soto, 2012) indica que el tiempo del que se dispone en el periodismo de investigación permite aplicar técnicas específicas de averiguación que ayudan a conocer más sobre los temas que están siendo ocultos intencionalmente. Al darse amplio rango de tiempo, las historias que investigan los periodistas suelen ser extensas, ya que se basan en la máxima cantidad de fuentes de información; de esta manera pueden tener la información completa y estar en capacidad de publicar la historia (Lee, 2013).

Adicional a lo planteado, el trabajo periodístico en la investigación periodística, debe ser de iniciativa propia, tener relevancia para algún sector de la población y buscar sacar a la luz algo deliberadamente oculto, como bien lo establece Flor (2016):

Producción propia; es decir, toda la investigación o la mayor parte de ésta debe ser del trabajo y autoría del periodista. Revelar hechos de trascendencia social, y que haya alguien que se empeñe en esconder al público el tema por el que es investigado. (p. 5)

Al respecto, Caminos (1997) señala que una de las características principales del periodismo de investigación tiene que ver justamente con el descubrimiento de la verdad oculta, por lo que es deber del periodista llegar hasta las últimas consecuencias en la búsqueda de la información que permita revelar y conocer los hechos.

Por otro lado, el proceso que se sigue en un trabajo de investigación periodística incluye cinco fases o 5 fases P, como señala de Pablos (1998):

1. Pista. Es el primer dato que llega a manos del periodista o al medio y que deja dudas acerca de un hecho, para luego ser propuesto como tema de 
investigación. A partir de la pista el periodista empiece a investigar; se debe generar un nudo informativo e interés para sus lectores. Es la fase más importante y donde se encuentra el «elemento disparador» (Lizárraga, 2019).

2. Pesquisa. El periodista debe comprobar mediante fuentes de información si la primera pista es un rumor o existen datos ocultos que puedan conducir a un hecho mayor. Se realiza los contactos con las fuentes y se recopila documentos que puedan revelar y aportar más información. Previamente el periodista plantea hipótesis como guía o derrotero de la investigación.

3. Publicación. La información pasa a ser publicada una vez que el periodista y el medio consideren que la historia está completa.

4. Presión. Se refiere a las presiones que ejercen las personas involucradas sobre los periodistas y/o el medio con el fin de evitar la publicación.

5. Prisión. Representa el cambio en el estatus del investigado, no necesariamente pérdida de la libertad.

\section{Las fuentes de información en el periodismo de investigación}

El trabajo con las fuentes de información resulta fundamental para garantizar el buen desarrollo de la investigación. Si bien el periodismo de investigación se basa en la revelación de hechos que son encubiertos deliberadamente, es gracias al acceso a fuentes y documentos, sean públicos o secretos, que se llega a conseguir recopilar información y corroborar los hechos (Lee, 2013).

En esta recolección es fundamental establecer qué son fuentes de información. Para Gans (1979, citado en Caminos, 1997) las fuentes son las personas o grupos de personas que suministran información y datos al periodista para que puedan ser publicadas. Las fuentes de información pueden ser documentales como entrevistas, libros, documentos o archivos que presenten datos relevantes y valiosos para la investigación. No obstante, es necesario que el periodista identifique también cuáles son las motivaciones de las fuentes que buscan revelar información, ya que podrían obedecer a motivaciones diversas como hacerse justicia por sus propias manos o venganza (Weibel, 2019). Precisamente, es labor del periodista verificar la información proporcionada por la fuente e indagar hasta corroborar lo obtenido. 
Por otro lado, el traspaso de información entre la fuente y el periodista puede darse bajo ciertas condiciones que implican la revelación o no de la identidad de quien revela la información. Caminos (1997) indica que, al momento de publicar la información, se presentan tres figuras que determinan el trabajo con las fuentes:

1. La información con atribución directa. La fuente autoriza al periodista a colocar su nombre en la publicación para que los lectores puedan identificarla, esto luego de pasar por una estricta verificación de la información proporcionada.

2. La información con atribución reservada. Es la práctica más frecuente en el trabajo con fuentes en el periodismo de investigación. La fuente pide no ser identificada en la divulgación o publicación de la investigación. Es común el uso de pseudónimos o nombres ficticios; también se puede referir a las fuentes como 'personas allegadas'.

3. La información para uso del periodista. Es la información proporcionada por las fuentes a los periodistas, pero sin dar permiso para su publicación; lo que también es útil porque aporta datos para interpretar, contextualizar y proceder con la investigación.

Al respecto, hay fuentes que autorizan que los investigadores revelen su identidad y otras que en cambio piden reserva. Los motivos expresados, por lo general, son el temor a represalias y temor a perder estatus o poder en la sociedad.

\section{La narración en el periodismo de investigación}

La redacción de la historia investigada es una de las partes más importantes del proceso, ya que de esto depende que el lector llegue al conocimiento y comprensión del caso. Es importante tener en cuenta que escribir una historia de investigación periodística no es igual a escribir un reportaje, una crónica o una nota informativa.

Uno de los primeros pasos que debe realizar el periodista es organizar y estructurar la información encontrada de manera jerárquica para determinar si hay o no vacíos en la historia que todavía merezcan ser investigados. El periodista debe elegir un método para informar a partir de hechos sólidos, en el que pueda sustentar lo investigado y a quién o qué busca denunciar (Reyes, 1996, como se citó en Alire, 2017). 
Desde el inicio debe delimitar cuál es el mensaje que pretende hacer llegar a los lectores, por lo tanto, para la redacción de una investigación periodística hay que tener una estructura narrativa definida para contar la historia. Las principales estructuras narrativas son la cronológica y la no lineal:

- En la estructura cronológica se plantean los hechos de manera ordenada de acuerdo al tiempo en que sucedieron. Si el periodista elige trabajar el texto con esta estructura, debe tener en cuenta primero la información que tiene a la mano para empezar la redacción, ya que la estructura cronológica funciona mejor cuando se quiere demostrar el punto de partida de la situación que llevó a investigar la historia (Lee, 2013).

- En la estructura no lineal, a diferencia de la estructura cronológica, no se sigue un orden, se presentan diversas unidades narrativas que están relacionadas entre sí (Zapata, s.f.).

Una vez definida la estructura narrativa con la que se contará la historia, se empieza con la redacción. Chicote (2006) señala que debe primar la organización de la información y pensar en la manera más atractiva de narrar los hechos para que estos sean de interés del lector. En este sentido, el uso de elementos narrativos o técnicas propias de la literatura ayudan al periodista a lograr el objetivo. De acuerdo a Lizárraga (2019), es necesario el uso de recursos literarios que ayuden a generar puntos de contraste entre los hechos y cambios de escenarios, pero sin dejar de lado el objetivo del autor, que es denunciar un hecho.

Sobre la descripción de escenas, Hoyos (2003, como se citó en Ramírez, 2014) indica que conducen a reconstruir los sucesos acontecidos para presentarlos al lector; como parte de la narración también están presentes las fuentes de información, quienes pasan a ser personajes caracterizados y con un carácter propio; los personajes aportan una mayor diversidad de voces a la historia y permiten contar los hechos.

\section{El Sodalicio de Vida Cristiana}

En la publicación Mitad monjes, mitad soldados (Salinas, 2016) se señala que, si bien la organización tiene sus orígenes a mediados de la década de los sesenta, no fue sino hasta inicios de los setenta que se constituye en un movimiento católico agrupando a jóvenes con el objetivo de servir plenamente a Dios. El Sodalicio de 
Vida Cristiana se fundó en 1971 como sociedad de derecho pontificio por el Beato Papa Juan Pablo II, la integran sodálites, adherentes, afiliados y cooperadores, «Sodalitium Christianae Vitae es una Sociedad de Vida Apostólica, integrada por laicos y sacerdotes que llevan vida fraterna en común, entregan su vida plenamente a Dios y anuncian el Evangelio en las diversas realidades humanas» (Sodalicio de Vida Cristiana, s.f.). En julio de 1997 la agrupación toma este nombre y para ese momento Luis Figari ya era uno de los principales líderes de la organización que fundó años atrás.

El Sodalicio de Vida Cristiana tiene sus orígenes en Perú, pero a medida que la institución fue creciendo se expandió a otros países. Tiene presencia en 17 países a nivel mundial, entre ellos Australia, Filipinas, España, Estados Unidos, Italia y todos los países de América Latina (Sodalicio, 2020). En el Perú, tiene nueve comunidades, cuatro se encuentran en Lima, dos en Arequipa y una en Piura, Ica y en la prelatura de Ayaviri respectivamente. Sin embargo, la presencia del Sodalicio no se limita solo a sus comunidades, ya que también posee universidades, centros educativos y centros culturales. Además, la organización cuenta con inmuebles, muebles y servicios con los que genera ganancias exoneradas de pagar impuestos (Grados, 2015).

De acuerdo a Peña (1995), la influencia del Sodalicio, doce años después, era notoria, similar a la del Opus Dei, reclutando obispos y otros miembros importantes de la iglesia católica peruana (Peña, 1995).

Una de las principales características del Sodalicio es su sólida organización jerárquica.

El sentido sectario del Sodalicio es innegable y se caracteriza por su relación estricta y definitiva entre los miembros del grupo y la creencia que son los poseedores de la verdad absoluta ... Además, la figura del líder está cargada de un peso muy fuerte en la organización. (Sáenz, 2005)

Desde esta perspectiva, el líder recibe una atención especial de parte de los otros miembros de la organización, respetando la jerarquía. El valor más destacado es la obediencia, que incluía cumplir horarios, determinadas formas de vestir e inclusive seguir carreras profesionales impuestas, así como el estudio de libros y materiales con ideologías fascistas, como señala Martín Scheuch, exsodálite, en entrevista con la periodista Pibhi (2016) de la BBC. 


\section{Metodología}

El tipo de investigación es aplicada y de nivel descriptivo explicativo, ya que es una problemática previamente delimitada en la que se exploran y analizan puntos específicos de informes periodísticos del caso Sodalicio. El diseño es no experimental, en la medida que se describen datos de una situación determinada.

Con respecto a la muestra, se consideran los informes publicados en la edición impresa del diario La República durante el año 2016. Son nueve informes, sus títulos y fechas correspondientes son los siguientes:

1. ¿ ¿Y qué fue de Figari y sus encubridores? (13 de marzo de 2016)

2. Jeffery Daniels, «el apóstol de los niños» (20 de marzo de 2016)

3. La fábrica del maltrato (27 de marzo de 2016)

4. La caída del Maciel peruano (10 de abril de 2016)

5. Al Sodalicio la muerte le sienta bien (20 de abril de 2016)

6. Ningún artista puede ser santo (24 de abril de 2016)

7. Jaime Baertl: El sacerdote que está detrás de los negocios del Sodalicio (6 de mayo de 2016)

8. Si no tomas tus pastillas, es pecado (9 de mayo de 2016)

9. ¿¿Dónde está mi denuncia, cardenal Cipriani? (12 de mayo de 2016)

La técnica y recolección de los datos se realizó mediante el uso de una matriz con los siguientes ítems: titular, sentido del texto introductorio, cuerpo narrativo, protección de fuentes y fuentes de información. Cada informe se analizó de acuerdo a esta estructura y en función de cuatro variables:

\section{Variable 1}

Criterios generales. Aspectos principales del informe que ofrecen al lector un primer acercamiento a la historia. Se realiza mediante dos indicadores:

- Titular: lo anunciado en el título del informe.

- Texto introductorio: el mensaje emitido debajo del titular. 
Variable 2

Elementos y características del periodismo de investigación. Análisis de acuerdo a los siguientes indicadores:

- Fases del periodismo de investigación: pista, pesquisa, publicación, presión y prisión (de Pablos, 1998).

- Fuentes de información: consultadas por los periodistas para recoger información sobre el caso.

- Protección a las fuentes: la manera en que son citadas las fuentes para no revelar su identidad.

Variable 3

Construcción narrativa. Elementos usados para revelar la información:

- Diseño de la estructura narrativa: puede ser cronológica o no lineal.

- Recursos literarios: descripción de escenas, uso de diálogos y demás recursos del periodismo literario.

- Diseño de personajes: construcción de personajes que tienen una participación en la historia.

Variable 4

Aspectos del Sodalicio de Vida Cristiana. La estructura de la organización:

- Miembros y cargos: personajes con una participación en la historia.

- Aspectos ritualísticos: pautas o guías realizadas en la institución.

- Formas de castigo: castigos y abusos físicos sufridos por los sodálites. 


\section{Resultados}

\section{Informe 1. ¿Y qué fue de Figari y sus encubridores?}

\section{Tabla 1}

Matriz de recojo de información del Informe 1

La República Informe 1

\section{3 de marzo de 2016}

Titular

Sentido del texto introductorio

Cuerpo narrativo

Protección de fuentes

Fuentes de información
¿Y qué fue de Figari y sus encubridores?

El texto informa sobre el escaso avance en la investigación de los abusos denunciados desde la publicación del libro (octubre de 2015) hasta la publicación de este informe (marzo de 2016).

- Estructura cronológica.

- Luis Figari como personaje principal del informe.

Uso de un seudónimo. «Santiago», es presentado como víctima de Luis Figari.

Se presentan entrevistas, documentales y de archivo:

- Diario La República, editorial 22/10/16.

- Primer comunicado del Sodalicio que busca marcar una posición de defensa de la institución.

- Segundo comunicado del Sodalicio firmado por su superior general Alessandro Moroni y en el que se comprometen a investigar las denuncias.

- Entrevista recuperada de Alessandro Moroni a El Comercio, donde indica que nunca se había sentido abusado cuando fue sodálite.

- Entrevista al monseñor Fortunato Urcey en RPP. Menciona que no hará investigaciones ni interrogatorios a Figari y que no dialogará con las víctimas. 


\section{Informe 2. Jeffery Daniels, «el apóstol de los niños»}

\section{Tabla 2}

Matriz de recojo de información del Informe 2

\section{La República \\ Informe 2}

20 de marzo de 2016

Titular

Sentido del texto introductorio

Cuerpo narrativo

Protección de fuentes

Fuentes de información
Jeffery Daniels, «el apóstol de los niños».

Se acusa a Daniels indicando dos datos sobre él: es señalado como pederasta por exsodálites y un presunto encubrimiento por el Sodalicio.

Estructura no lineal.

Uso de seudónimo para contar el testimonio de una víctima de Jeffery Daniels, presentado como «Tito». Se describen los comportamientos que Daniels tuvo con él y otros jóvenes que tenía a su cargo.

- Testimonio de «Tito», recogido del libro Mitad monjes, mitad soldados.

- Entrevista a Mauro Bartra, exsodálite, quien revela comportamientos inadecuados de Daniels.

- Entrevista recuperada de Alessandro Moroni a El Comercio, que indica las medidas tomadas sobre las acusaciones a Daniels.

- Testimonios de exsodálites testigos de comportamientos de Daniels y de lo ocurrido en San Bartolo.

- Fernando Vidal, asistente de comunicaciones del Sodalicio, quien hizo una breve referencia al tema.

- Entrevista al psiquiatra Carlos Mendoza, presunto profesional que trató a Daniels. 


\section{Informe 3. La fábrica del maltrato}

\section{Tabla 3}

Matriz de recojo de información del Informe 3

\section{La República Informe 3}

27 de marzo de 2016

Titular

Sentido del texto introductorio

Cuerpo narrativo

Protección de fuentes

Fuentes de información

\section{La fábrica del maltrato}

Se muestra una entrevista de Vidal con la BBC en la que se refiere a las acusaciones de abuso como "casos aislados». Se busca conocer cuál es el sistema de formación (bajo el que ocurrirían los abusos) dentro del Sodalicio de Vida Cristiana.

Estructura no lineal.

Se menciona el testimonio de «exsodálites», que prefieren no revelar su nombre.

Se presentan entrevistas realizadas a exsodálites:

- Entrevista a Eduardo Ayala y Gustavo Salinas, quienes cuentan sobre el sistema de castigos en el Sodalicio.

- Entrevista a exsodálite que menciona a Tokumura como responsable de los castigos recibidos.

- Oscar Osterling acusa a Alessandro Moroni y Figari de haber perpetrado castigos abusivos.

- Otro exsodálite menciona las secuelas que tuvo en él los abusos que sufrió de parte de Daniel Cardó y Alfredo Cabrera.

- Entrevista a Elías Mindreau, quien cuenta cómo eran obligados a jugar con sandalias.

- Entrevista a Martín Balbuena, quien narra una de las prácticas que consistía en correr descalzos distancias largas.

- Entrevista a Juan Carlos Jarufe.

- Entrevista al psicoanalista Jorge Bruce. 


\section{Informe 4. La caída del Maciel peruano}

\section{Tabla 4}

Matriz de recojo de información del Informe 4

La República Informe 4

\section{0 de abril de 2016}

Titular

Sentido del texto introductorio

Cuerpo narrativo

Protección de fuentes

Fuentes de información
La caída del Maciel peruano.

El texto habla sobre la salida de Luis Figari del Sodalicio y el impacto que tuvo en las personas que veían en él a alguien admirable.

Estructura no lineal.

Testimonio de «exsodálites», quienes no revelan su nombre.

- Vídeo de YouTube donde Moroni se refiere a la separación de Figari de la institución.

- Juan Armando Lengua Balbi, abogado de Luis Figari.

- Entrevista a Rocío Figueroa, exsuperiora de la Fraternidad Mariana de la Reconciliación, rama femenina del Sodalicio, otra víctima de la institución.

- Entrevista a sodálite quien menciona la responsabilidad de otros miembros del Sodalicio frente a los abusos.

- Entrevista a José Enrique Escardó, víctima del Sodalicio quien habla sobre el proceso de reestructuración.

- Entrevistas a sodálites y exsodálites que hablan sobre la reforma de la institución.

- Columna de opinión de Ronald Gamarra, exprocurador anticorrupción.

- Entrevista a Pablo Pérez en el diario El País.

- Comunicado de la Santa Sede sobre las acciones a tomar en el grupo Los legionarios de Cristo.

- Cita del libro El imperio financiero de Los Legionarios, de Raúl Olmos. 


\section{Informe 5. Al Sodalicio la muerte le sienta bien}

\section{Tabla 5}

Matriz de recojo de información del Informe 5

La República

\section{0 de abril de 2016}

Titular

Sentido del texto introductorio

Cuerpo narrativo

Protección de fuentes

Fuentes de información

\section{Informe 5}

Al Sodalicio la muerte le sienta bien.

No se presenta texto introductorio.

Estructura no lineal.

Presentan las denuncias y documentos respecto al manejo de los cementerios propiedad del Sodalicio.

Luego se menciona sobre el caso del sacerdote Ferroggiaro y una posible acusación en su contra por supuestas conductas impropias.

Se menciona a «fuentes internas del Sodalicio» quienes señalan sobre una regularización de los movimientos financieros del Sodalicio.

- Se menciona la lectura de documentos, a los que tuvieron acceso, donde se registra el uso de los fondos de mantenimiento.

- Se cita la ley N. 26298 de Cementerios y Servicios Funerarios.

- Se menciona un intento de comunicación, sin éxito, con el director gerente de Cementerio Parque del Recuerdo, Raúl Guinea.

- Denuncia realizada por Víctor Raúl Cáceres Lazo, ante la Dirección General de Salud Ambiental.

- Marco Antonio Huaco, experto en Concordato, explica sobre acuerdo entre el Vaticano y el Estado peruano. 


\section{Informe 6. Ningún artista puede ser santo}

\section{Tabla 6}

Matriz de recojo de información del Informe 6

La República Informe 6

24 de abril de 2016

Titular

Sentido del texto introductorio

Cuerpo narrativo

Protección de fuentes

Fuentes de información
Ningún artista puede ser santo.

El informe final de la Comisión de Ética para la Justicia y la Reconciliación atribuyó como veredicto final los abusos sindicados al Sodalicio. Si bien la comisión escuchó los testimonios de las víctimas para llegar a sus conclusiones, hay algunas que no contaron su historia.

Estructura cronológica.

No se presenta.

- Entrevista a Martín Pérez del Solar, víctima del Sodalicio, que da cuenta de los abusos sufridos en la institución.

- Informe final de la Comisión de Ética para la Justicia y la Reconciliación. 


\section{Informe 7. Jaime Baertl: El sacerdote que está detrás de los negocios del Sodalicio}

\section{Tabla 7}

Matriz de recojo de información del Informe 7

La República Informe 7

6 de mayo de 2016

Titular

Jaime Baertl: El sacerdote que está detrás de los negocios del Sodalicio.

Sentido del texto introductorio

Se refiere al papel que tiene Jaime Baertl, sacerdote del Sodalicio, en las finanzas de la institución. Recordemos que en un informe anterior se mencionó las inversiones que manejaba la institución.

Cuerpo narrativo

Estructura cronológica.

Protección de fuentes

Se hace mención a «fuentes cercanas» y «testimonios de exsodálites» en tres ocasiones.

La información está relacionada con los negocios del Sodalicio por medio de Inversiones San José y la conducta de Baertl.

Fuentes de información

- Marco Antonio Huaca

- Fuente personal

- Distintos documentos que responden a los manejos financieros de la institución. 


\section{Informe 8. Si no tomas tus pastillas, es pecado}

\section{Tabla 8}

Matriz de recojo de información del Informe 8

\section{La República \\ Informe 8}

9 de mayo de 2016

Titular

Sentido del texto introductorio

Cuerpo narrativo

Protección de fuentes

Fuentes de información
Si no tomas tus pastillas, es pecado.

Menciona que, más allá de las secuelas psicológicas que presentan algunos exsodálites luego de su paso por la institución, existe también una dificultad para volver a adaptarse y reinsertarse a la sociedad.

Estructura cronológica.

Se hace mención a un exsodálite, quien da cuenta de los manejos de informes psicológicos de los sodálites.

- José Humberto García, exsodálite. El informe lo cita en varias ocasiones para contar su experiencia.

- Rodrigo Mora, exsodálite, da su versión sobre el testimonio de García.

- Se cita al blog del exsodálite Martín Scheuch, donde se cuenta sobre los exámenes y evaluaciones psicológicas realizadas en el Sodalicio. 


\section{Informe 9. ¿Dónde está mi denuncia, cardenal Cipriani?}

\section{Tabla 9}

Matriz de recojo de información del Informe 9

\section{La República \\ Informe 9}

\section{2 de mayo de 2016}

Titular

Sentido del texto introductorio

Cuerpo narrativo

Protección de fuentes

Fuentes de información
¿Dónde está mi denuncia, cardenal Cipriani?

Las denuncias emitidas contra Figari, que fueron enviadas aparentemente a Roma por el cardenal Cipriani y el presidente del Tribunal Eclesiástico, no dan señales de encontrarse allí. ¿Qué se hicieron con esas denuncias?

Estructura cronológica.

Se menciona una denuncia por abuso sexual, presentada por una «víctima» contra Luis Figari, ante el Tribunal Eclesiástico.

- ACI Prensa 2014, testimonio de Erwin Scheuch sobre las denuncias contra Cipriani.

- Carta de «Santiago» enviada al diario El Comercio.

- Programa radial de RPP en el que Luis Gaspar se refiere a las denuncias contra Figari.

- Declaraciones de Natale Amprimo, abogado de Cipriani, sobre las denuncias contra Figari.

- Programa radial del 30 de octubre, de Luis Cipriani, en el que se refiere a las denuncias contra Figari.

- Carta de «Santiago» publicada en La Mula el 4 de noviembre de 2015.

- Correo electrónico del vicario general del Sodalicio, José Ambrozic a «Santiago», enviado el 4 de mayo. 


\section{Discusión}

\section{Criterios generales}

Los titulares de los nueve informes varían en la forma, pero se evidencia un punto en común que es el cuestionamiento por los hechos y los implicados en el abuso. Encajan en tres tipologías:

1. Titulares de informes que se caracterizan por mencionar a un personaje de la historia, y que se plantean de manera descriptiva o interrogativa.

- Informe 1: ¿¿Y qué fue de Figari y sus encubridores?

- Informe 2: Jeffery Daniels, «el apóstol de los niños»

- Informe 3: La caída del Maciel peruano

- Informe 7: Jaime Baertl: El sacerdote que está detrás de los negocios del Sodalicio.

- Informe 9: ¿Dónde está mi denuncia, cardenal Cipriani?

2. Titulares de informes que se caracterizan por cuestionar a un personaje de la historia, y que se plantean de manera interrogativa.

- Informe 1: ¿¿Y qué fue de Figari y sus encubridores?

- Informe 9: ¿¿Dónde está mi denuncia, cardenal Cipriani?

3. Titulares de informes compuestos por una cita textual, con lo que se busca dar voz a los personajes de la historia.

- Informe 6: Ningún artista puede ser santo

- Informe 8: Si no tomas tus pastillas, es pecado

- Informe 9: ¿Dónde está mi denuncia, cardenal Cipriani?

Los textos introductorios, que son un primer acercamiento de la historia que se brinda al lector, están diseñados de manera descriptiva. 


\section{Elementos y características del periodismo de investigación}

Es el análisis de acuerdo a los indicadores: fases del periodismo de investigación, fuentes de información y protección a las fuentes.

En las fases del periodismo de investigación: pista, pesquisa, publicación, presión y prisión (de Pablos, 1988):

Fase 1. Pista: En el primer informe se mencionan las columnas de opinión de José Enrique Escardó publicadas en el año 2000, donde relata haber sufrido abusos cuando perteneció a la institución. No es la primera información que tienen los autores, pero sí es la primera información que se hizo pública, por lo tanto, se considera como la primera fase.

Fase 2. Pesquisa: Se corrobora y valida la primera pista y se hace uso de las fuentes de información. Se identifican tres temas principales:

- Abusos físicos, psicológicos y sexuales: Identificado como el punto central en el caso Sodalicio, se presentan distintos testimonios y documentos que dan cuenta de los abusos cometidos en la institución.

- Sanciones y encubrimientos: Se presentan testimonios que señalan pocas o nulas sanciones para los victimarios, todos miembros de la institución; dan cuenta del encubrimiento en la institución.

- Negocios e inversiones: Se señalan algunas actividades que sostienen financieramente al Sodalicio. No hay datos o hechos concretos sobre un mal manejo en las inversiones, pero sí se presenta una posible irregularidad en una sepultura de un cementerio de propiedad del Sodalicio.

Fase 3. Publicación: Corresponden a esta fase los nueve informes publicados en el diario La República.

Fase 4. Presión: No se señala presión ejercida por los investigados sobre el periodista y el medio informativo; sin embargo, sí se denuncia la actitud de los miembros del Sodalicio al negarse a ofrecer información sobre los implicados y los hechos mismos. Se complica así la labor de los periodistas para encontrar mayor evidencia, lo que puede ser interpretado como una presión. 
Fase 5. Prisión: En el informe 4 se indica que Luis Figari es separado de la institución para ser enviado a Roma y la posterior reestructuración del Sodalicio. No ocurrió pérdida de la libertad del investigado, pero sí un cambio en su estatus a raíz de lo publicado.

Se identifican tres tipos de fuentes de información en los informes: entrevistas, documentales y de archivo. Existen testimoniales, legales, periodísticos y emitidos por especialistas. Son un total de 50 fuentes de información.

La protección a las fuentes de información se realiza mediante el uso de pseudónimos, utilizando un nombre ficticio para evitar que sean identificados; también información con atribución reservada utilizando frases ambiguas como exsodálites, fuentes internas del Sodalicio o fuentes cercanas a.

\section{Construcción narrativa}

Para revelar la información se consideraron tres indicadores:

1. En la estructura narrativa, el $60 \%$ de los informes tiene una estructura cronológica, es decir, se narra la historia de manera secuencial a partir de lo señalado por las víctimas. También, hay informes con estructura no lineal, en los que no se plasmó de manera completa el testimonio de las víctimas, sino que se hizo un recuento de los acontecimientos que evidenciaban los abusos.

2. Se identifican dos recursos literarios, recreación de escenas y uso de diálogos. En el Informe 6 y en el Informe 8 se recrean escenas, en el Informe 3 se usa diálogos. El poco uso de recursos literarios en los informes es porque la intención de los periodistas es poner en evidencia los abusos perpetrados al interior de la institución mediante la recopilación de testimonios e indagación de los hechos.

3. La construcción de los personajes también forma parte de los recursos literarios, pero en este caso se considera de manera individual. El diseño o construcción de personajes se realiza en función de la participación de personajes en la historia, considerados principales y secundarios. Los principales se identifican según tres dimensiones: personal, laboral e intervención en la historia como víctima o victimario. 
Son identificados como personajes principales los siguientes:

- Luis Fernando Figari, es nombrado como personaje principal en los informes 1 y 9 por su participación en el caso, ya que además de ser uno de los denunciados, es el fundador del Sodalicio y fue su líder máximo por más de treinta años. En cuanto a las dimensiones de caracterización encontradas se puede indicar que desde una dimensión personal, si bien no se presentan detalles de la vida personal de Figari, sí se resalta su cercanía con Germán Doig, otro exmiembro y líder en el Sodalicio acusado de pederastia; desde una dimensión laboral, se presentan datos que muestran un posible encubrimiento a Figari, además se muestra también cómo era visto por los sodálites cuando aún permanecía en el Sodalicio; según se relata, era considerado como un ser superior. En cuanto a su intervención en la historia, los informes muestran dos acusaciones contra Figari por abuso sexual contra exsodálites, por lo que es un victimario en el caso.

- Alessandro Moroni, actual superior general del Sodalicio, es nombrado a lo largo de toda la cobertura ya que es la voz oficial de la institución. En la dimensión laboral, resulta ser la persona con mayor rango al interior del Sodalicio. En consecuencia, su intervención en la historia está sujeta a su participación por el cargo máximo.

- Jeffery Daniels es mencionado en el segundo informe, considerado como uno de los personajes principales por las acusaciones que recaen sobre él, además de encontrarse elementos que permiten caracterizarlo. En este sentido, desde la dimensión personal se conoce que ingresó al Sodalicio durante su juventud debido a su cercanía con la Iglesia católica. Sobre su personalidad, una de sus víctimas lo define como una persona «inteligente y astuta, de sonrisa fácil». Sobre la dimensión laboral, el segundo informe lo menciona como «el apóstol de los niños», ya que tenía a su cargo a un grupo de jóvenes aspirantes a sodálites. Su intervención en la historia se resume a los abusos sexuales de los que lo acusan. Además de presentarse testimonios de sus víctimas directas, existen testimonios que lo acusan de tener comportamientos de carácter sexual.

- Álvaro Urbina es la primera víctima de Jeffery Daniels que no oculta su identidad. Desde una dimensión personal, Urbina ingresó al Sodalicio cuando aún era menor de edad e integró uno de los grupos de jóvenes que dirigía Daniels. Sobre su intervención en la historia, es considerado una víctima ya que relata los abusos sexuales que sufrió por parte de Daniels. 
En cuanto a los personajes secundarios, se puede establecer una larga lista de personas participantes en la historia. Para facilitar la identificación se organizan tres grupos: (1) las víctimas, (2) las personas que tienen un vínculo con el Sodalicio y otra entidad religiosa y (3) las personas que tengan alguna intervención en la historia.

1. Víctimas:

- José Enrique Escardó: primera víctima denunciante de los abusos en el Sodalicio.

- Rocío Figueroa: primera víctima femenina de la que se conoce su testimonio. Fue superiora de la Fraternidad Mariana de la Reconciliación, rama femenina del Sodalicio.

- «Tito»: exsodálite víctima de abuso sexual de Jeffery Daniels.

- «Santiago»: una de las víctimas denunciantes de Luis Fernando Figari por abuso sexual.

- Mauro Bartra: exsodálite testigo de uno de los comportamientos indebidos de Jeffery Daniels.

- Eduardo Ayala: exsodálite que cuenta su experiencia en una de las casas de formación del Sodalicio.

- Carlos Adrianzén

- Gustavo Salinas: exsodálite, cuenta su experiencia como integrante.

- Oscar Osterling: exsodálite por veinte años, cuenta su experiencia como integrante de la institución.

- Elías Mindreau: miembro del Sodalicio por cinco años y víctima de abusos físicos.

- Martín Balbuena: exsodálite que permaneció en la institución por seis años y fue víctima de abuso físico.

- Juan Carlos Jarufe: miembro del Sodalicio por 12 años y víctima de abuso psicológico.

- Martín Scheuch 
- Jason Day: denunciante.

- Franz Guillén: exsodálite.

- Sodálite chileno: exsodálite mencionado en el informe.

- Rodrigo Mora: exsodálite quien da testimonio sobre lo ocurrido con José García.

2. Miembros del Sodalicio y de otras entidades religiosas:

- Fernando Vidal: asistente de comunicaciones y vicario general del Sodalicio, encargado de emitir algunos de los comunicados en los que se refieren a las denuncias presentadas contra algunos miembros de la institución.

- Víctor Huapaya: sacerdote y presidente del Tribunal Eclesiástico.

- Monseñor Fortunato Pablo Urcey: designado visitador apostólico para investigar sobre las denuncias.

- Oscar Tokumura: miembro del Sodalicio, superior en la comunidad de San Bartolo.

- Luis Gaspar: sacerdote y juez en el Tribunal Eclesiástico.

- Juan Luis Cipriani: cardenal de Lima.

- Fernando Lino: jefe de prensa del Arzobispado de Lima.

- Alfredo Garland: miembro del Sodalicio.

- German Doig: exmiembro del Sodalicio, acusado de abuso sexual contra menores y encargado del colegio San Pedro.

- Daniel Cardó: miembro del Sodalicio, acusado de imponer prácticas físicas abusivas.

- Alfredo Cabrera: miembro del Sodalicio, acusado de imponer prácticas físicas abusivas.

- Eduardo Regal: miembro del Sodalicio.

- Erwin Scheuch: miembro del Sodalicio acusado de abuso psicológico. 
- José Antonio Eguren: arzobispo de Piura y Tumbes, acusado de encubrir los abusos denunciados en el Sodalicio.

- Alfredo Draxl: miembro del Sodalicio, exdirector del colegio San Pedro y acusado de abuso físico por José Enrique Escardó.

- Jurguen Daum: sacerdote y miembro del Sodalicio.

- Enrique Elías Dupuy: procurador del Sodalicio en Roma.

- Raúl Guinea: director gerente de Cementerios Parque del Recuerdo, de propiedad del Sodalicio.

- Violeta Ordoñez de Guinea: esposa de Raúl Guinea.

- Luis Ferrogiaro Dentone: sacerdote acusado por Jason Day y otro sodálite por actos impropios.

- Rossana Echeandía: experiodista de El Comercio perteneciente a una de las organizaciones femeninas del Sodalicio y que habló sobre la denuncia de Jason Day en una de sus columnas de opinión en el diario en mención.

- Daniel Murguía: sodálite a cargo de Martín Pérez del Solar. Murguía fue encarcelado por pederasta en el 2007.

- Ricardo Treneman: sodálite acusado de actos impropios por Pérez del Solar.

- Rafael Ísmodes: miembro del Sodalicio, perteneciente al colegio San Pedro.

- Javier Len: perteneciente a Inversiones San José.

- Gonzalo Zen: miembro del Sodalicio, encargado del colegio San Pedro.

- Javier del Río: arzobispo de Arequipa quien pidió el retiro de un sacerdote sodálite de su jurisdicción.

- Mario Rivarola Morán: perteneciente a Inversiones San José.

- Ernesto Vallejos: perteneciente a Inversiones San José.

- Juan Carlos Len: perteneciente a Inversiones San José.

- Javier Alvarado: sacerdote sodálite y consejero espiritual de José García.

- Germán McKenzie: miembro del Sodalicio y superior de José García. 
- Virgilio Levaggi: miembro del Sodalicio, perteneciente a Inversiones San José y a la «generación fundacional».

- Emilio Garreaud: miembro del Sodalicio, perteneciente a la «generación fundacional».

- José Ambrozic: vicario general del Sodalicio.

- Javier Alvarado: sacerdote sodálite y consejero espiritual de José García.

3. Personajes con otra participación en el caso:

- Pablo Sánchez: fiscal de la nación encargado de abrir una investigación sobre las denuncias.

- María del Pilar Peralta: fiscal encargada de investigar las denuncias por el caso Sodalicio.

- Juan Armando Lengua: abogado de Luis Fernando Figari.

- Carlos Mendoza Angulo: psiquiatra quien habría dado tratamiento a Jeffery Daniels durante su aislamiento en San Bartolo.

- Jorge Bruce: psicoanalista consultado por los autores para ofrecer su punto de vista sobre algunas prácticas sodálites.

- Ronald Gamarra: exprocurador anticorrupción quien se refiere a la reestructuración del Sodalicio en su columna del semanario Hildebrandt en sus trece.

- Natale Amprimo: abogado de Juan Luis Cipriani.

- Víctor Raúl Cáceres Lazo: denunciante del Parque del Recuerdo en Lurín por presuntas irregularidades en una sepultura.

- Marco Antonio Huaco: experto en concordato que explica sobre el acuerdo entre el Estado peruano y la Iglesia católica.

- Juan José Cueto: perteneciente al grupo empresarial chileno Cueto, con quien Baertl tuvo una relación de negocios.

- Julio Navarro: jefe de prensa del Ministerio Público. 
Asimismo, los personajes son agrupados según su participación:

1. El primer grupo son las víctimas, que testimonian abusos de parte de líderes del Sodalicio, de índole físico, sexual y psicológico.

2. El segundo grupo, personajes que ocupan algún cargo en el Sodalicio o que cumplen alguna función dentro de la Iglesia católica: victimarios o acusados, miembros del Sodalicio sin acusaciones, así como miembros de la iglesia que ofrecieron declaraciones a la prensa refiriéndose al tema.

3. El tercer grupo de personajes son ajenos a ambas instituciones, en su mayoría profesionales consultados sobre el tema.

Los aspectos del Sodalicio de Vida Cristiana incluyen la estructura de la organización y sus lineamientos funcionales.

Con respecto a los miembros y cargos, en los informes se mencionan varios miembros de la institución, la mayoría de ellos son acusados de abusos. De acuerdo al cargo ejercido se analiza la participación en los hechos:

- Alessandro Moroni, es destacado por asumir el cargo de superior general luego de la salida de Figari. Ostentando el cargo más alto en la institución, fue quien aprobó y dirigió el tenor de las declaraciones y comunicados referidos a las denuncias de abuso.

- Fernando Vidal, vicario general y asistente de comunicaciones del Sodalicio, es nombrado reiteradamente en los informes. Se encargaba de responder a los medios de comunicación y administrar los comunicados e informaciones oficiales del Sodalicio.

- El Consejo Superior del Sodalicio, en este caso la información es escasa sobre los nombres de sus miembros; son quienes toman las decisiones en el Sodalicio.

La institución tiene una estructura organizacional lineal muy definida en la que prima el principio de la jerarquía. Se evidencia el respeto y obediencia al jefe superior o líder de la institución. Frente al destape de las investigaciones solo el Superior General y la oficina de comunicaciones se hicieron cargo de los descargos y comunicados en la prensa. 
En cuanto a los aspectos ritualísticos, es posible identificar las pautas que se siguen con el ingreso de nuevos miembros a la institución; por ejemplo, en el informe 8 se menciona como requisito que deben ser personas jóvenes, en edad escolar, a las que se les debe evaluar durante su etapa de formación con pruebas psicológicas y otros instrumentos.

Finalmente, en cuanto a las formas de castigo en el Sodalicio, según los informes se caracterizaban por aceptación de la violencia física como parte de la formación sodálite. Por ejemplo, en el Informe 1 se le acusa a Moroni de prácticas abusivas físicas y psicológicas contra sodálites; en el Informe 3 se mencionan castigos físicos impuestos a los sodálites, como golpes y hasta prácticas físicas extremas; en el Informe 6 se da cuenta de castigos dejándolos sin comida a los sodálites por dos días. Por tanto, la violencia física se normalizaba, eran prácticas cotidianas al interior de la institución y en la que se ponía en peligro la integridad física y emocional de los sodálites.

\section{Conclusiones}

Se analizan las características de investigación periodística en nueve informes sobre el caso Sodalicio, que se publicaron en el diario La República entre marzo y mayo del 2016. En los informes se da cuenta de los testimonios de víctimas de abusos físicos, sexuales y psicológicos ocurridos dentro de la institución católica denominada Sodalicio de Vida Cristiana. Asimismo, se señala como principales responsables de abusar de menores de edad, a miembros de la institución que ejercían liderazgo, como es el caso de Luis Figari, fundador y director durante dos décadas.

El contenido de cada uno de los nueve informes se estructura de acuerdo a los siguientes ítems: titular, sentido del texto introductorio, cuerpo narrativo, protección de fuentes y fuentes de información.

Los titulares de los informes se plantean de manera descriptiva, interrogativa o mediante una cita textual; mencionan personajes y situaciones. De la misma manera descriptiva se presentan los textos introductorios. Mientras el cuerpo narrativo de los informes cumple con los elementos del periodismo de investigación: es una investigación de autoría propia, presenta hechos de trascendencia social y revela hechos ocultos deliberadamente por un grupo de poder; también, se cumplen las cinco fases del periodismo de investigación: pista, pesquisa, publicación, presión y prisión (de Pablos, 1998). 
Se encuentran fuentes de información de tipo entrevista, documentales y de archivo. Son constantes las fuentes personales, es decir, testimonios de personajes directamente relacionados con la historia. Además, se protege fuentes mediante el uso de pseudónimos o la frase «información con atribución reservada».

Los informes, en su mayoría, tienen una estructura cronológica para desarrollar la información. Se destacan el uso de recursos literarios como la descripción de escenas, uso de diálogos y en menor cantidad la construcción de personajes, ya que el objetivo de los autores es enfocarse en los testimonios de las víctimas que sufrieron los abusos.

El Sodalicio de Vida Cristiana, de acuerdo a los informes, mantiene un orden jerárquico donde la figura del líder es el máximo representante. En este contexto, los testimonios revelan abusos de orden físico, sexual y psicológico, de manera recurrente, cometidos por líderes de la institución.

Finalmente, los nueve informes corresponden a un trabajo propio del periodismo de investigación en el que se presentan elementos narrativos relacionados al periodismo literario.

\section{Referencias}

Alire, L. M. (2017). Situación actual del periodismo de investigación en la prensa escrita de Arequipa: La República, Correo, Noticias y El Pueblo, 2016 [Tesis de licenciatura, Universidad Nacional San Agustín]. Arequipa.

Caminos, J. M. (1997). Periodismo de investigación. Teoría y práctica. Editorial Síntesis S.A. https://periodismodeinvestigacion.files.wordpress.com/2012/04/documento-011.pdf

Chicote, J. (2006). Los enemigos del periodismo de investigación. Revistas Científicas Complutenses, 12, 71-90. https://revistas.ucm.es/index.php/ESMP/article/view/ESMP060 6110071A

de Pablos, J. M. (1998). Periodismo de investigación: las cinco fases P. Revista Latina de Comunicación Social, 9. http://www.revistalatinacs.org/a/475fp.htm

Flor, E. (2016). Guía de Periodismo de Investigación. UNESCO. https://antezanacc.com/docs/ Guia_de_Periodismo_de_Investigacion.pdf

García, G. (1996, 19 de octubre). El mejor oficio del mundo. El País (Sociedad). https:// elpais.com/diario/1996/10/20/sociedad/845762406_850215.html 
Grados, L. (2015, 29 de diciembre). Exclusivo: Estas son las millonarias empresas que sustentan al investigado Sodalicio de Vida Cristiana SAC. Útero.pe. http://utero.pe/2015/ 12/29/estas-son-las-millonarias-empresas-que-sustentan-al-investigado-sodalicio-de-vidacristiana-sac/

Kovach, B. y Rosenstiel, T. (2012). Los elementos del periodismo. Aguilar.

Lee, M. (2013). La investigación a partir de historias: manual para periodistas de investigación. UNESDOC, Biblioteca digital. https://unesdoc.unesco.org/ark:/48223/ pf0000226457

Lizárraga, D. (2019, 15 de enero). 10 elementos que no pueden faltar en una investigación periodística, según Daniel Lizárraga. Fundación Gabo. https://fundaciongabo.org/es/ noticias/articulo/10-elementos-que-no-pueden-faltar-en-una-investigacion-periodisticasegun-daniel

Martínez-Sanz, R. y Durántez-Stolle, P. (2019). El ejercicio del periodismo de investigación en España. La percepción de su estado actual. Revista Latina de Comunicación Social, 74, 822-839. http://www.revistalatinacs.org/074paper/1359/42es.html

Peña, M. (1995). Theologies and Liberation in Peru. The Role of Ideas in Social Movements. Temple University Press.

Pibhi, P. (2016, 14 de marzo). El Sodalicio, el grupo religioso internacional que enfrenta acusaciones por abusos sexuales en Perú. BBC Mundo. https:/www.bbc.com/mundo/ noticias/2016/03/160105_america_latina_peru_sodalicios_denuncias_abuso_sexual_ppb

Ramírez, L. (2014). Periodismo Literario o Narrativo del siglo XXI [Tesis de maestría, Universidad Nacional Autónoma de México].

Sáenz, M. (2005). Las vocaciones religiosas en los jóvenes. Estudio del caso Sodalitium Christianae Vitae [Tesis de licenciatura, Pontificia Universidad Católica del Perú]. Lima.

Salinas, P. (2016). Mitad monjes, mitad soldados (2. ${ }^{\text {a }}$ ed.). Planeta.

Sodalicio de Vida Cristiana. (s.f.). ¿Qué es la familia Sodálite? https://sodalicio.org/que-esla-familia-sodalite/

Soto, M. (2012). Periodismo de investigación en América Televisión, técnicas y herramientas usadas en el desarrollo de tres casos de denuncia periodística sobre corrupción: Elsa Canchaya, Walter Menchola y Banco de Materiales (2007-2008) [Tesis de licenciatura, Universidad Nacional Mayor de San Marcos].

Weibel, M. (2019). Manual de periodismo de investigación: ética / narrativa / investigación / seguridad. UNESCO. 
Zapata, G. (s.f.). Narrativa No Lineal. \#Multimedia Storytelling: arte y técnica de la narración transmediática (Unidad Didáctica 4). XDOC.MX. https://xdoc.mx/documents/ narrativa-no-lineal-5f2db91d6093f 